\title{
Pilot Study of the Dynamic Effects of Simulated Axial Loading Magnetic Resonance Imaging in Lumbar Disc Herniation
}

\author{
Juan Antonio Aguilera-Repiso*, Luis García-Bordes, Massimo Feliciani, Ángeles Zamora-Solà, \\ Joan Bagó-Granell, Gerard Urrutia-Cuchi, Juan Carlos Serfaty-Soler, Ernest Lucas-Andreu and \\ Xavier Gómez-Bonsfills
}

MC-Mutual, Copernico, 58. 08006, Barcelona, Spain

\begin{abstract}
Study Design: A pilot study of lumbar disc herniation patients examined with magnetic resonance imaging in both psoas-relaxed position and axial compression in extension of the lumbar spine is described. Objective: To discuss the clinical value of axially loaded magnetic resonance imaging in patients with lumbar disc herniation and to evaluate the effect on the dural cross-sectional area. Summary of Background Data: Magnetic resonance imaging tests are performed in a supine relaxed position. It is well documented that a narrowing of the spinal canal is provoked by axial loading, especially when it is combined with spinal extension. Physiological or pathological changes due to loading effects might thus remain undetected by conventional imaging tests. This unloading effect could lead surgeons to a diagnosis that does not take into account these dynamic aspects. The present pilot study seeks to evaluate the effect of axial loading compression on the dural cross-sectional area in patients with lumbar disc herniation. The purpose of this study is to help surgeons in making treatment decisions or surgery indications. Methods: 15 patients underwent magnetic resonance imaging examinations in both psoas-relaxed position and axial compression in extension using a compression device $\left(\right.$ DynaWell $^{\circledR}$ ). An axial load corresponding to $50 \%$ of the body weight was applied. Changes in the dural cross-sectional area were registered. Results: A significant decrease in dural cross-sectional area was found in only 2 patients (13.3\%). In 13 patients, no significant changes in dural cross-sectional area were found. Concerning the overall results, no significant differences were observed between both MRI. Conclusions: Using magnetic resonance imaging, no statistical significant decrease in dural cross-sectional area after axial loading was found. These findings do not support the recommendation of magnetic resonance imaging with axial compression in patients with sciatica secondary to lumbar disc herniation.
\end{abstract}

Keywords: Axial compression, disc herniation, magnetic resonance imaging, sciatica.

\section{INTRODUCTION}

Imaging tests performed to detect and describe degenerative spinal disease (plain X-rays, computed tomography scan (CT) and magnetic resonance imaging (MRI)) are performed in a supine relaxed position. It is well documented that a narrowing of the spinal canal is provoked by axial loading, especially when it is combined with spinal extension [1-11]. Physiological or pathological changes due to loading effects might thus remain undetected by conventional MRI. This unloading effect could lead surgeons to a diagnosis that does not take into account these dynamic aspects.

Several imaging studies have shown spinal canal diameter changes after using axial loading devices [6-11]. However, the clinical impact of these changes is not completely clear.

The present pilot study seeks to evaluate the effect of axial loading compression on the dural cross-sectional area in patients with lumbar disc herniation.

\section{MATERIAL AND METHODS}

This is a cross sectional study involving the application of two tests (one conventional MRI in psoas relaxed position

*Address correspondence to this author at the MC-Mutual, Copernico, 58. 08006, Barcelona, Spain; Fax: 0034-932000694; Tel: 0034-934141992; E-mails: 1luisgarbo@yahoo.com, jaguilera@mc-mutual.com and another one with axial compression in extension) on a recruited sample of 15 consecutive patients complaining for sciatic pain. This is a complancency number of patients as this is a preliminary study.

The axial compression device we used is DynaWell ${ }^{\circledR}$. Results of both MRI were compared, and the change in dural cross-sectional area between positions was calculated. Secondary, we studied the correlation between the MRI results and surgical findings.

DynaWell $^{\circledR}$ (DynaWell Int. AB. Billdal. Sweden) is a compression device used to perform axially loaded examinations in order to simulate the standing position. The patient wears an adjustable harness that hugs the shoulders and upper chest; this harness is then attached to a compression platform placed on his feet using nylon straps. During the procedure, these straps are tightened to apply the desired load (up to $50 \%$ of patients' body weight), compressing the spine similar to the standing position (Fig. 1). The loading time was just the necessary to perform the MRI, not exceeding twenty minutes in any case.

Inclusion criteria included: 6-12 week long radicular pain secondary to lumbar disc herniation and unsuccessful conservative treatment. Being a pilot study, we initially used a convenience sample of 15 patients, established from the available funding to cover additional costs. 


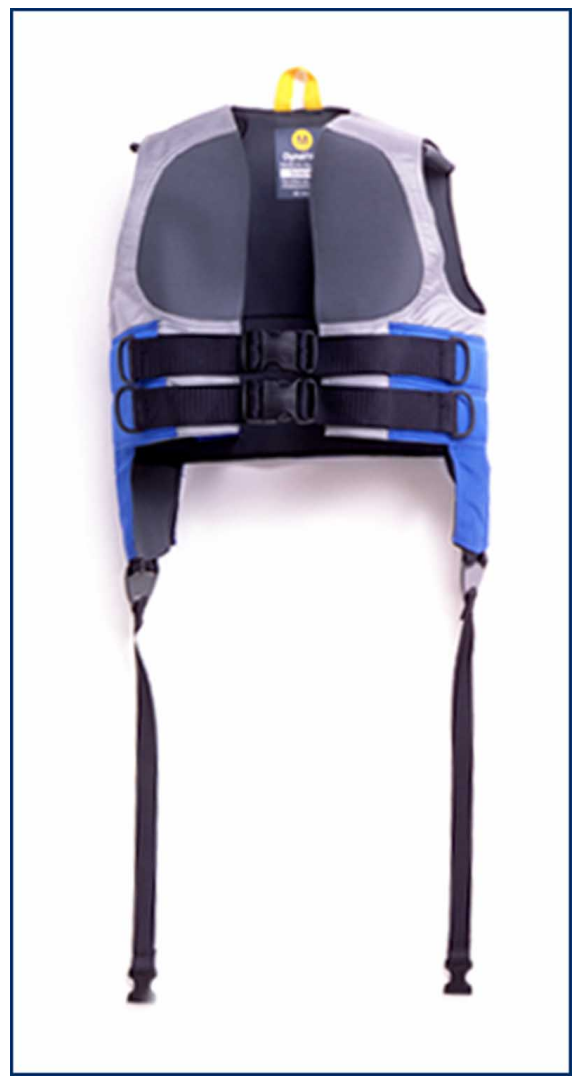

Fig. (1). DynaWell ${ }^{\circledR}$ compression device.

All MRI were evaluated independently by two neuroradiologists. All patients were operated by the same surgeon and assistant. In addition to the usual contraindications for the implementation of MRI, there are some contraindications for using DynaWell ${ }^{\mathbb{B}}$ like spinal trauma, spinal tumor and severe osteoporosis.

In the evaluation of MRI before and after application of DynaWell $^{\mathbb{B}}$ we considered the deformity of the dural sac (dural cross-sectional area variation) as the most reliable parameter, which also allows quantitative studies (Table 1).

Table 1. Definition of Stenosis According to AP Diameter and Measurement of the Dural Sac Area

- Definition of stenosis according to AP diameter:

- $10-12 \mathrm{~mm}=$ relative stenosis

$\bullet<10 \mathrm{~mm}=$ absolute stenosis

- Measurement of the dural sac area:

->130 $\mathrm{mm}^{2}=$ normal

$\cdot 130-100 \mathrm{~mm}^{2}=$ mild stenosis

- 75-100 $\mathrm{mm}^{2}$ = relative stenosis

- $<75 \mathrm{~mm}^{2}=$ absolute stenosis

For herniated discs, peroperative findings were classified according to Carragee's classification criteria [12].

\section{RESULTS}

An amount of 15 patients were finally studied (12 men and 3 women). The average age was 41.2 years (range 2757).
Dural sac area average was $1.76 \mathrm{~cm}^{2}\left( \pm 0.44 \mathrm{~cm}^{2}\right)$ in conventional uncompressed MRI. The MRI with axial compression $\left(\right.$ DynaWell ${ }^{\mathbb{B}}$ ) revealed a dural cross-sectional area average of $1.73 \mathrm{~cm}^{2}\left( \pm 0.43 \mathrm{~cm}^{2}\right)$. Three cases $(20 \%)$ had mild estenosis $\left(1.18 \mathrm{~cm}^{2}, 1.27 \mathrm{~cm}^{2}\right.$ and $\left.1.29 \mathrm{~cm}^{2}\right)$, the rest had a normal dural sac area. There was significant modification of the dural cross-sectional area only in two cases $(13.3 \%)$. These two cases were contained herniations (Case 1: $2.25 \mathrm{~cm}^{2}$ pre-load $/ 2 \mathrm{~cm}^{2}$ post-load; Case 13: 1.88 $\mathrm{cm}^{2}$ pre-load $/ 1.68 \mathrm{~cm}^{2}$ post-load). Concerning the overall results, no significant differences were observed between both MRI.

Taking into account Carragee's classification criteria, the operative findings were 10 contained discal herniations and 5 not contained discal herniations. No difference between MRI and surgical findings was found in this study.

Inter-rater agreement (kappa) for two radiologists was 0.84 .

\section{DISCUSSION}

Lumbar pain represents important social and health costs in industrialized countries and the leading cause of disability in population over 45 years of age $[13,14]$. The prevalence of sciatica in the course of life is $80 \%$, representing the main reason for medical consultation, as well as the leading cause of absenteeism in these countries. It is the first cause of working days lost In the USA. In Europe, low back pain is the most disability disease in terms of loss of working days, between 45 and 64 . Around $20 \%$ of these patients develop chronic sciatica. In the United States, 5.2 million people suffer from some type of limitation secondary to chronic back pain.

Imaging tests performed to detect and describe the degenerative spinal disease include plain X-rays, computed tomography (CT) and magnetic resonance imaging (MRI). All these tests are performed in a supine relaxed position. It is well documented that a narrowing of the spinal canal is provoked by axial loading, especially when it is combined with spinal extension which results in unloading of the spine with discrete lumbar extension and enlargement of the canal $[1,2]$. Discal changes due to loading effects might thus remain undetected by conventional imaging tests.

Lumbar spine biomechanics causes spinal canal diameter changes in sitting and standing position [3-5]. For this reason, conventional $\mathrm{CT}$ and MRI examinations practiced in a rest position are characterized by the relaxation of the psoas muscle [Psoas Relaxed Position (PRP)], reducing thereby the load on the spine and thus increasing the diameter of the spinal canal. This unloading effect could lead surgeons to a diagnosis that does not take into account these dynamic aspects. Thus, some pathological changes could be missed like disc herniation, canal stenosis or listhesis.

DynaWell ${ }^{\circledR}$ is an axial compression device developed to simulate the condition of standing position in supine extension (Sweden). Several studies have shown that the use of the DynaWell ${ }^{\mathbb{B}}$ can cause a diameter reduction of the spinal canal compared with routine MRI technique [6-10], depending on the axial load applied and the loading time. However, the clinical impact of the changes induced by 
DynaWell $^{\circledR}$ is not completely clear, although some studies suggest may help in making treatment decisions or surgery indications [11].

Even though the findings of this study are in line of the previous studies, in the current study the axial loading MRI helped only to detect the spinal canal narrowing in $13 \%$ of the patients. Our results revealed no statistical difference between both MRI methods (conventional vs. axial loading MRI).

Some limitations have been found in our study, such as a small sample (15 patients). The loading time may be too short in order to provoke discal prolapse. Inter-rater agreement (kappa) for two radiologists studying MRI was similar to other publications [15].

Comparing our findings with those of the previous studies, some authors describe that MRI after axial loading detects better the spinal narrowing in older patients and at L4-L5 level. It seems that the patients in our study were younger than other studies (average 41.2 years). This could be another limitation to take into account.

Our goal is to reach a correct diagnose and to treat properly these patients. In today's medicine, it is an ethical need to know the accuracy of diagnostic tests and to know their limitations. We must use imaging tests when necessary, trying always to avoid misdiagnose and overtreatment. To conclude, we must consider not using MRI with simulated standing position as a routine test in patients with lumbar disc herniation. This study does not seem to help surgeons in making treatment decisions or surgery indications.

\section{REFERENCES}

[1] Panjabi MM, Takata K, Goel VK. Kinematics of lumbar intervertebral foramen. Spine 1983; 8: 348-57.

[2] Penning L, Wilmink JT. Biomechanics of the lumbosacral dural sac. A study of flexion-extension myolography. Spine 1981; 6 (4): 398-408.
[3] Coulier B. Evaluation of lumbar canal stenosis: decubitus imaging methods versus flexion-myelografphy and surface measurements versus the diameter of the dural sac. JBR-BTR 2000; 83(2): 61-7.

[4] Schönström NSR, Lindahl S, Willén J. Dynamic changes in the dimensions of the slumbar spinal canal. An experimental study in vitro. J Orthop Res 1989; 7: 115-21.

[5] Inufusa A, An HS, Lim TH, et al. Anatomic changes of the spinal canal and intervertebral foramen associated with flexion-extension movement. Spine 1996; 21: 2412-20.

[6] Willén J, Danielson B, Gaulitz A, et al. Dynamic effects on the lumbar spinal canal: axially loaded CT-myelography and MRI in patients with sciatica and/or neurologic claudication. Spine 1997; 22: 2968-76.

[7] Danielson BI, Willén J, Gaulitz A, et al. Axial loading of the spine during $\mathrm{CT}$ and MR in patients with suspected lumbar spinal stenosis. Acta Radiol 1998; 39: 604-11.

[8] Danielson B, Willén J. Axially loaded magnetic resonance image of the lumbar spine in asymptomatic individuals. Spine 2001; 26: 2601-6.

[9] Willén J, Danielson B. The diagnostic effect from axial loading of the lumbar spine during computed tomography and magnetic resonance imaging in patients with degenerative disorders. Spine 2001; 26: 2607-14.

[10] Danielson B, Willén J. Axially loaded CT and MRI of the lumbar spine - A method to achieve an accurate radiological diagnosis in patients with low back pain. Chapter 9. Advances in Spinal Fusion. Marcel Dekker, Inc, New York 2003; pp. 1-13.

[11] Hiwatashi A, Danielson B, Moritani T, et al. Axial loading during MR imaging can influence treatment decision for symptomatic spinal stenosis. Am J Neuroradiol 2004; 25: 170-4.

[12] Carragee E, Han M, Suen P, et al. Clinical outcomes after lumbar discectomy for sciatica: the effects of fragment type and anular competence. J Bone Joint Surg 2003; 85: 102-8.

[13] Cats-Baril WL, Frymoyer JW. The economics of spinal disorders. In: Frymoyer JW, Ed. The adult spine: principles and practice. New York: Raven Press, 1991: pp. 85-105.

[14] Norlund AI, Wadell G. Cost of back pain in some OECD countries. In: Nachemson AL, Jonsson E, Eds. Neck and back pain. the scientific evidence of causes, diagnosis, and treatment. Philadephia: Lippingcott Williams \& Wilkins 2000: pp. 421-5.

[15] Pfirrmann CW, Metzdorf A, Zanetti M, et al. Magnetic resonance classification of lumbar intervertebral disc degeneration. Spine 2001; 26: 1873-8.

\footnotetext{
Received: August 11, 2011

(C) Aguilera-Repiso et al.; Licensee Bentham Open.
}

Revised: October 17, 2011

Accepted: October 24, 2011

This is an open access article licensed under the terms of the Creative Commons Attribution Non-Commercial License (http://creativecommons.org/licenses/by$\mathrm{nc} / 3.0 /$ ), which permits unrestricted, non-commercial use, distribution and reproduction in any medium, provided the work is properly cited. 